available carbonates can take place at depth and hence be greatly in advance of any nearsurface oxidation processes. This was demonstrated in the Yorkshire Main Colliery tip investigations (Spears et al., 1971). Most of the gypsum in the tip was derived from coal waste from underground and $\mathrm{X}$ ray studies confirmed that gypsum occurred with carbonates (ankerite and calcite) and kaolinite on the faces of the coal cleat. The carbonates post-date the jointing (cleating) of the coal, and are indicative of ground water flow at depth. The coal was the source of the subsequently oxidized pyrite.

Pyrite decomposes readily during weathering but monitoring the breakdown by means of the $\mathrm{Fe}_{2} \mathrm{O}_{3}: \mathrm{FeO}$ ratio could be misleading. Although pyrite $\left(\mathrm{FeS}_{2}\right)$ is a ferrous mineral the standard redox titration method does not determine the $\mathrm{Fe}^{2+}$ attributable to pyrite. Pyrite is included in colorimetrically determined $\mathrm{Fe}_{2} \mathrm{O}_{3}$ values, i.e. total iron minus $\mathrm{FeO}$. There are theoretical approaches for obtaining an $\mathrm{Fe}^{3+}$ figure which is independent of total iron, but the real problem in conventional analytical methods is to get pyrite into solution and still obtain a correct $\mathrm{FeO}$ value. Some of the variation in Dr Chandler's $\mathrm{Fe}_{2} \mathrm{O}_{3}: \mathrm{FeO}$ ratios is probably a function of pyrite content.

From the weathering scheme adopted (Table 1), chemical changes along fissures (zone II) are partly related to the availability (hence origin) of the discontinuities. In a weathering study of in situ coal measures shales and mudstones at a site near Rotherham, Yorkshire (Spears and Taylor, 1972), the 'lithorelicts in matrix' (三 to zone III) did not exceed $1.98 \mathrm{~m}$ in depth. For these older, more indurated rocks the depth would appear to be generally less than that for the Lias. It will be of interest to see if in the absence of too much climaticvegetation variation, an approximate age (induration) relationship with zone III depth of weathering is applicable to shale-type rocks in Britain.

\title{
REFERENCES
}

Siever, R. (1959). Petrology and geochemistry of silica cementation in some Pennsylvanian sandstones. Soc, Econ. Palaeont Mineralogy, Special Publication No. 7, 55 - 79.

Spears, D. A., Taylor, R. K., \& Till, R. (1971). A mineralogical investigation of a spoil heap at Yorkshire Main Colliery. Q. Jnl Engng Geol. 3, 239-252.

Spears, D. A. \& Taylor, R. K. (1972). The influence of weathering on the composition and engineering properties of in situ coal measures rocks. Int. Inl Rock Mech. Min. Sci. 9, 729-756.

\section{Prediction of undrained deformations and pore pressures in weak clay under two embankments}

\author{
RAYMOND, G. P. (1972). Géotechnique 22, No. 3, 381-431.
}

\section{G. J. W. King, Civil Engineering Department, Liverpool University}

The Author maintains that a transversely isotropic elastic model is more unlikely to predict smaller immediate settlements than an isotropic one. His opinion is influenced largely by the restriction he placed on the upper limit of the independent shear modulus $G_{\mathrm{u}}$ (Raymond, 1970) after considering the expression

$$
\sigma_{z}=\frac{P_{z}}{2 \pi} \frac{1}{\sqrt{ } \alpha-\sqrt{ } \beta}\left[\frac{1}{\left(r^{2}+\frac{z^{2}}{\alpha}\right)^{3 / 2}}-\frac{1}{\left(r^{2}+\frac{z^{2}}{\beta}\right)^{3 / 2}}\right]
$$

quoted by Barden (1963) for the vertical stress at a point $(r, z)$ in a semi-infinite transverselyisotropic elastic medium because of a point load $p$ on its surface. The reasoning in other papers (Hollingshcad and Raymond, 1971, 1972) has also been influenced by this restriction. 
Raymond (1970) simplified Barden's expressions for the parameters $\alpha$ and $\beta$ so that

and

$$
\left.\begin{array}{r}
\alpha \beta=\frac{E_{\mathrm{v}}}{E_{\mathrm{h}}} \frac{\left(1-\nu_{\mathrm{h}}^{2}\right)}{\left(1-E_{\mathrm{h}} \nu_{\mathrm{v}}^{2} / E_{\mathrm{v}}\right)} \\
(\alpha+\beta)=\frac{E_{\mathrm{v}}-2 G_{\mathrm{v}} \nu_{\mathrm{v}}\left(1+\nu_{\mathrm{h}}\right)}{G_{\mathrm{v}}\left(1-E_{\mathrm{h}} \nu_{\mathrm{v}}^{2} / E_{\mathrm{v}}\right)}
\end{array}\right\}
$$

in which the elastic constants $E_{\mathrm{h}}$ and $\nu_{\mathrm{h}}$ are associated with the isotropic $x y$ planes and $E_{\mathrm{v}}$, $\nu_{\mathrm{v}}$ and $G_{\mathrm{v}}$ with planes containing the unique $z$ axis.

The Author assumed that real values of $\sigma_{\mathrm{z}}$ could only be calculated for real values of $\alpha$ and $\beta$ and hence derived an upper limit for the independent shear modulus $G_{\mathrm{v}}$, expressed as a function of $E_{\mathrm{h}}, E_{\mathrm{v}}, \nu_{\mathrm{h}}$ and $\nu_{\mathrm{v}}$. Values in excess of this limit have been used by King and Chowdhury (1970) when computing stresses beneath strip loads on transversely-isotropic foundations and therefore the validity of the limit must be questioned.

Expanding the terms

$$
\left(r^{2}+\frac{z^{2}}{\alpha}\right)^{-3 / 2}
$$

and

$$
\left(r^{2}+\frac{z^{2}}{\beta}\right)^{-3 / 2}
$$

in equation (1) and combining terms a series is obtained in which the $(p+1)$ th term is

$$
\left(\frac{-\frac{3}{2}}{P}\right)\left(r^{2}\right)^{P}\left(\frac{z^{2}}{\alpha}\right)^{-3 / 2-P}-\left(\frac{z^{2}}{\beta}\right)^{-3 / 2-P}
$$

For given values of $r$ and $z$ this term is a function of

$$
\alpha^{3 / 2+P}-\beta^{3 / 2+P}
$$

Now $\sigma_{z}$ will be real if all terms

$$
t_{p+1}=\left(\alpha^{3 / 2+P}-\beta^{3 / 2+P}\right) /(\sqrt{ } \alpha-\sqrt{ } \beta)
$$

are real. Simplifying

$$
t_{p+1}=\frac{\alpha^{P+2}-\beta^{P+2}+\sqrt{ } \alpha \beta\left(\alpha^{P+1}-\beta^{P+1}\right)}{\alpha-\beta} \quad . \quad . \quad . \quad .
$$

Since $\frac{\alpha^{m}-\beta^{m}}{\alpha-\beta}$ can be expressed entirely as a function of $(\alpha+\beta)$ and $\alpha \beta$ using the recurrence formulae

$$
\alpha^{m}-\beta^{m}=(\alpha-\beta)\left(\alpha^{m-1}+\beta^{m-1}\right)+\alpha \beta\left(\alpha^{m-2}-\beta^{m-2}\right)
$$

and

$$
\alpha^{m}+\beta^{m}=(\alpha+\beta)\left(\alpha^{m-1}+\beta^{m-1}\right)-\alpha \beta\left(\alpha^{m-2}-\beta^{m-2}\right)
$$

the only requirement for $t_{p+1}$ to be real is that $(\alpha+\beta)$ and $\alpha \beta$ are real. This is so for all real values of the elastic constants. (Note that the vertical stress at depth $z$ vertically below the point load, obtained from equation (1), is simply

$$
\left(\sigma_{z}\right)_{r=0}=\frac{P}{2 \pi z^{2}}((\alpha+\beta)+\sqrt{ } \alpha \beta)
$$

and that this corresponds to the first term $t_{p+1}=t_{1}$ in equation (3) with $p=0$.)

Therefore equation (1) yields real stresses for all values of $G_{\mathrm{v}}$. The only restriction on this constant is $G_{v}>0$ as given by Hearmon (1961). It follows that overestimated settlements 
of embankments and foundations resulting from the assumption of isotropy might be attributed to anisotropy.

\section{REFERENCES}

Barden, L. (1963). Stresses and displacements in a cross-anisotropic soil. Géotechnique 13, No. 3, 198-250. Hearmon, R. F. S. (1961). An introduction to applied anisotropic elasticity. Oxford: Clarendon Press.

Hollingshead, G. W. \& Raymond, G. P. (1971). Prediction of undrained movements caused by embankments on muskeg. Can. Geotech. Jnl 8, No. 1, 23-35.

Hollingshead, G. W. \& Raymond, G. P. (1972). Field loading tests on muskeg. Can. Geotech. Jnl 9, No. $3,278-289$.

King, G. J. W. \& Chowdhury, R. N. (1970). Stresses due to strip loads on anistropic soil. Symp. shallow foundations, Indian Nat. Soc. Soil Mech. Fdn Engng, Bombay, 94-99.

Raymond, G. P. (1970). Discussion on Stresses and displacements in a cross-anisotropic soil. Géotechnique 20, No. 4, 456-458.

\section{G. P. Raymond}

The Author wishes to thank Mr King for his observations regarding the incorrect restriction placed on the independent shear modulus $G_{\mathrm{v}}$. A similar point has been made by Gerrard (1972). For the special case of undrained movements, which is the subject from the Paper under discussion, the following formulae may be taken from Raymond (1970)

equation (8)

$$
\begin{aligned}
& \nu_{\mathrm{v}}=\frac{1}{2} \\
& \nu_{\mathrm{h}}=1-\frac{1}{2} \frac{E_{\mathrm{h}}}{E_{\mathrm{v}}}
\end{aligned}
$$

equation (9)

equation (15)

$$
\rho_{r}=\frac{P}{2 \pi r} \sqrt{\left[\frac{1-\frac{E_{\mathrm{h}}}{4 E_{\mathrm{v}}}}{E_{\mathrm{v}} G_{\mathrm{v}}}\right]}
$$

Provided the restriction that under plane strain conditions an increase in horizontal load (which could be done in a laboratory test) will not cause a decrease in stress and thus a tensile stress in the horizontal direction, i.e. the zero strain direction, then $\nu_{h}$ must be positive. Under these circumstances the major errors in the present method of estimating immediate or undrained settlement analysis resulting from cross-anisotropy will occur from not measuring and accounting for $G_{\mathrm{v}}$. Only a maximum $19 \%$ error occurs from knowing $E_{\mathrm{v}}$ and $G_{\mathrm{v}}$ and assuming $E_{\mathrm{h}}=E_{\mathrm{v}}$. Since $E_{\mathrm{v}}$ is the quantity normally measured, then any calculations assuming isotropy under undrained conditions would assume $G_{\mathrm{v}}=E_{\mathrm{v}} / 3$. If anisotropy is to be used to explain a $100 \%$ overestimation of the measured undrained settlements then $G_{v}$ must be $2 \cdot 7$ times this value combined with $E_{\mathrm{h}}=2 E_{\mathrm{v}}$. In soft deposits $E_{\mathrm{v}}$ will probably be larger than $E_{\mathrm{h}}$ requiring $G_{\mathrm{v}}$ to be many times larger.

It is unfortunate that many theoretical analyses get presented without what statisticians term a sensitivity analysis. However, such an analysis, as briefly given, brings one to the conclusion that it is unlikely that cross-anisotropy will explain large overestimations of immediate undrained zero dilation settlements. This will become even less likely in soft or weak soil deposits where $E_{\mathrm{h}}$ is likely to be less than $E_{\mathrm{v}}$.

Any experimental data $\mathrm{Mr}$ King may have on realistic undrained values of $G_{\mathrm{v}} / E_{\mathrm{v}}$ would be most welcome.

\section{REFERENCES}

Gerrard, C. M. (1972).

22, No. 2, 372-376.

Raymond, G. P. (1970).

20, No. 4, 456-458.

Discussion on Stresses and displacements in a cross-anisotropic soil. Géotechnique

Discussion on Stresses and displacements in a cross-anisotropic soil. Géotechnique 